\title{
Phaeosaccardinula coffeicola and Trichomerium chiangmaiensis, two new species of Chaetothyriales (Eurotiomycetes) from Thailand
}

\section{Maharachchikumbura $\mathrm{SSN}^{1,2}$, Haituk $\mathrm{S}^{1}$, Pakdeeniti $\mathbf{P}^{1}$, Al-Sadi $\mathbf{A M}^{2}$, Hongsanan $S^{3}$, Chomnunti $P^{3}$, Cheewangkoon $R^{1}$}

\author{
${ }^{1}$ Entomology and Plant Pathology Department, Faculty of Agriculture, Chiang Mai University \\ ${ }^{2}$ Department of Crop Sciences, College of Agricultural and Marine Sciences, Sultan Qaboos University, P.O. Box 34, \\ 123 Al-Khoud, Oman \\ ${ }^{3}$ Center of Excellence in Fungal Research, Mae Fah Luang University, Chiang Rai 57100, Thailand
}

Maharachchikumbura SSN, Haituk S, Pakdeeniti P, Al-Sadi AM, Hongsanan S, Chomnunti P, Cheewangkoon R 2018 - Phaeosaccardinula coffeicola and Trichomerium chiangmaiensis, two new species of Chaetothyriales (Eurotiomycetes) from Thailand. Mycosphere 9(4), 769-778, Doi 10.5943/mycosphere/9/4/5

\begin{abstract}
Two species of sooty mould-like taxa, were obtained from living leaves of Coffea arabica plants collected in Chiang Mai Province, Thailand. Differences in phenotypic and phylogenetic characteristics based on combined large subunit nuclear ribosomal DNA and internal transcribed spacer sequences indicated that the two isolates represent two novel species (Phaeosaccardinula coffeicola and Trichomerium chiangmaiensis) within the order Chaetothyriales. Phaeosaccardinula coffeicola (Chaetothyriaceae) is distinguished morphologically from related species by its smaller asci and ascospores. Trichomerium chiangmaiensis (Trichomeriaceae) is morphologically distinguishable from its phylogenetically related species by its smaller conidial arms. Detailed taxonomic descriptions and illustrations of the new species are provided.
\end{abstract}

Key words - Chaetothyriaceae - Coffea arabica - new species - sooty mould - Trichomeriaceae

\section{Introduction}

The order Chaetothyriales was introduced by Barr (1976) for Loculoascomycetes that presence of with periphysoids (apical paraphyses) in the ascomata (Winka et al. 1998). Barr (1987) accepted Chaetothyriaceae, Coccodiniaceae, Herpotrichiellaceae, Metacapnodiaceae, Microtheliopsidaceae, Pyrenotrichaceae, Strigulaceae and Trichopeltidaceae as families of Chaetothyriales. In the classification of Wijayawardene et al. (2018), ten families are accepted in Chaetothyriales: Chaetothyriaceae, Coccodiniaceae, Cyphellophoraceae, Epibryaceae, Herpotrichiellaceae, Lyrommataceae, Microtheliopsidaceae, Pyrenotrichaceae, Strelitzianaceae and Trichomeriaceae. Members belonging to the order Chaetothyriales are morphologically highly diverse both in their ascomycetous sexual morphs and dematiaceous hyphomycetous asexual morphs (Gueidan et al. 2008, Chomnunti et al. 2012a, Dong et al. 2018). Species of Chaetothyriales are common in tropical and temperate ecosystems and may cause plant diseases, have also been recorded as an opportunistic human and animal pathogens, often isolated as saprobes, or occur as lichenized taxa or epilithic fungi (Gueidan et al. 2008, Chomnunti et al. 2012a, Réblová et al. 2013, Liu et al. 2015, Hongsanan et al. 2016, Hyde et al. 2016, Teixeira et al. 2017, Dong et al. 2018). 
The Chaetothyriaceae was introduced by Hansford (1946) and members belonging to the family are saprotrophic or biotrophic (Chomnunti et al. 2012a, 2014, Hongsanan et al. 2016). The Chaetothyriaceae includes 16 genera, including the foliar epiphytic genus Phaeosaccardinula, which has superficial ascomata, with a dark, non-setose pellicle, saccate, bitunicate asci and muriform, hyaline to brownish ascospores (Batista et al. 1962, Hughes et al. 1976, Yang et al. 2014). Phaeosaccardinula was described by Hennings (1905) with $P$. diospyricolai as the type species. Many of the species belonging to the Phaeosaccardinula were later transferred to the genera Limacinula and Treubiomyces (Reynolds 1971, 1983) and it has an estimated 14 species (Kirk et al. 2008, Yang et al. 2014, Wijayawardene et al. 2017).

Trichomeriaceae was introduced by Chomnunti et al. (2012a) and placed in Chaetothyriales based on analysis of LSU and ITS sequence data. The family comprises a single genus, Trichomerium, with its type species $T$. coffeicola. Chomnunti et al. (2012a) proposed $T$. foliicola as the type species of Trichomerium, since it has been impossible to obtain the holotype specimen of T. coffeicola and also no molecular data exists in worldwide databases for this species or genus. The foliar epiphyte genus Trichomerium occurs superficially on living leaves of a variety of plants (Chomnunti et al. 2012a). It is estimated that the genus includes 23 species (Kirk et al. 2008), however, only seven species have sequence data. Trichomeriaceae was synonymized under Chaetothyriaceae by Réblová et al. (2013) based on ITS- $\beta$-tubulin-LSU-SSU-RPB2-mcm7 phylogeny and assessment of ITS secondary structures. However, Trichomeriaceae was accepted as a distinct family in most subsequent studies based on multi-gene phylogenetic analysis (Gueidan et al. 2014, Liu et al. 2015, Hyde et al. 2016).

We have been carrying out a taxonomic survey of foliar epiphytes on Coffea arabica (coffee) plants in Thailand and in the present study, two new species, Phaeosaccardinula coffeicola and Trichomerium chiangmaiensis, are introduced. Evidence for the new species is based on their unique morphological characters, as well as the support from phylogenetic analyses of combined LSU and ITS sequence data.

\section{Materials \& Methods}

\section{Isolation and identification of fungi}

Fungi with sooty mould-like colonization were collected in 2014 from coffee leaves in Chiang Mai Province, Thailand. Specimens were taken to the laboratory in envelopes. Measurements and descriptions of sections of the ascomata/conidiomata, asci and ascospores/condia were carried out by immersing ascomata/conidiomata in water or in Shear's reagent. Unless otherwise stated, all photographs and measurements were made from material mounted in water and 95\% lactic acid. Slides were viewed under a Nikon SMZ745T stereo microscope and (Axiovision Zeiss Scope-A1) microscope where diagnostic morphological features were recorded photomicrographs and measurements were taken. The fungal species present on the substrate were isolated using a single spore culture technique. In short, an ascomata/ conidiomata was immersed in $300 \mu \mathrm{l}$ of sterile distilled water on a slide and left for a few minutes, so that the ascospores were discharged. An ascospore suspension was made, small drops were placed on water agar (WA) in Petri-dishes and kept at room temperature for 8-12 h for ascospores to germinate; single germinating ascospores were transferred to potato dextrose agar (PDA) plates. The plates were incubated at $25{ }^{\circ} \mathrm{C}$ for 15 to 20 days. After a month, the growing cultures were used for molecular work. Holotype specimens are deposited in herbarium of Chiang Mai University and living cultures are deposited in Sultan Qaboos University culture collection (SQUCC). Facesoffungi and Index Fungorum numbers are registered as outlined in Jayasiri et al. (2015), Index Fungorum (2018).

\section{DNA isolation, amplification and Sequencing}

Total genomic DNA was extracted directly using a DNA extraction kit (E.Z.N.A. Forensic DNA Kit), following the protocols in the manufacturer's instructions. For nucleotide sequence 
comparisons, the internal transcribed spacer region (ITS) and a segment of the large subunit rDNA (LSU) regions were amplified using primer pairs ITS4/ITS5 (White et al. 1990) and LROR/LR5 (Vilgalys \& Hester 1990), respectively. The thermal cycling program followed Maharachchikumbura et al. (2014). Sequencing of the PCR amplicons was conducted using the same primers used for the amplification reactions. The PCR products were verified by staining with ethidium bromide on $1 \%$ agarose electrophoresis gels. DNASTAR Lasergene SeqMan Pro v.8.1.3 was used to obtain consensus sequences from sequences generated from forward and reverse primers and these were subsequently lodged in GenBank (Table 1).

\section{Phylogenetic analysis}

The sequences generated in this study were supplemented by additional sequences obtained from GenBank, based on BLAST searches and the literature. Multiple sequence alignments were generated with MEGA v.7.0.26 (Kumar et al. 2016) and the alignment was visually improved where necessary. Phylogenetic analyses of the sequence data consisted of Maximum Parsimony (MP) and Maximum Likelihood (ML) analyses of the aligned datasets. A maximum likelihood analysis was performed using RAxMLGUI v. 1.3 (Silvestro \& Michalak 2012). The optimal ML tree search was conducted with 1,000 separate runs, using the default algorithm of the program from a random starting tree for each run. The final tree was selected among suboptimal trees from each run by comparing likelihood scores under the GTR+GAMMA substitution model evolution by MrModeltest 2.2 (Nylander 2004). The MP analysis was performed with PAUP v.4.0b10 (Swofford 2003). Trees were inferred by using the heuristic search option with TBR branch swapping and 1,000 random sequence additions. The maximum number of retained trees was limited to 5,000, branches of zero length were collapsed and all multiple equally most parsimonious trees were saved. Tree length (TL), consistency index (CI), retention index (RI), rescaled consistency index (RC), homoplasy index (HI), and log likelihood (-ln L) (HKY model) values were calculated. The robustness of the equally most parsimonious trees was evaluated by 1,000 bootstrap replications (Felsenstein 1985) resulting from a maximum parsimony analysis, each with 10 replicates of random stepwise addition of taxa. The resulting trees were printed with MEGA v.7.0.26 (Kumar et al. 2016) and the layout was made with Adobe Illustrator CS v.6.

Table 1 Details of the strains included for molecular study and newly generated sequences are indicated in bold

\begin{tabular}{llll}
\hline Taxon & Isolate & \multicolumn{2}{c}{ GenBank accessions } \\
\cline { 3 - 4 } & & LSU & ITS \\
\hline Aphanophora eugeniae & CBS 124105 & FJ839652 & NR_132829 \\
Bradymyces alpinus & CCFEE 5493 & GU250396 & NR_132844 \\
Brycekendrickomyces acaciae & CBS 124104 & FJ839641 & NR_132828 \\
Camptophora hylomeconis & CBS 113311 & - & NR_132881 \\
Capronia mansonii & CBS 101.67 & NR_121262 & AY004338 \\
Ceramothyrium ficus & MFLUCC 15-0229 & KT588600 & KT588602 \\
Ceramothyrium ficus & MFLUCC 15-0228 & KT588599 & NR_154800 \\
Ceramothyrium menglunense & MFLUCC 16-1874 & KX524146 & NR_154813 \\
Ceramothyrium podocarpi & CPC 19826 & KC005795 & NR_120227 \\
Ceramothyrium thailandicum & MFLUCC 10-0008 & KP324930 & NR_137768 \\
Cladophialophora minourae & CBS 556.83 & FJ358235 & AY251087 \\
Cyphellophora fusarioide & MUCL 44033 & KC455252 & NR_132879 \\
Cyphellophora guyanensis & MUCL 43737 & KC455253 & NR_132880 \\
Cyphellophora olivacea & CBS 122.74 & KC455260 & KC455247 \\
Cyphellophora oxyspora & CBS 698.73 & KC455262 & NR_132883 \\
\hline
\end{tabular}


Table 1 Continued.

\begin{tabular}{|c|c|c|c|}
\hline \multirow[t]{2}{*}{ Taxon } & \multirow[t]{2}{*}{ Isolate } & \multicolumn{2}{|c|}{ GenBank accessions } \\
\hline & & $\mathbf{L S U}$ & ITS \\
\hline Cyphellophora reptans & CBS 113.85 & JQ766493 & NR_121346 \\
\hline Epibryon diaphanum & M122 & EU940101 & - \\
\hline Epibryon hepaticola & M10 & EU940091 & JX298885 \\
\hline Epibryon interlamellare & M223 & EU940135 & - \\
\hline Epibryon plagiochilae & M187 & EU940124 & - \\
\hline Exophiala eucalyptorum & CBS 121638 & KC455258 & KC455245 \\
\hline Exophiala xenobiotica & CBS 115831 & FJ358246 & AY857539 \\
\hline Fonsecaea monophora & CBS 102243 & FJ358247 & EU938579 \\
\hline Knufia cryptophialidica & DAOM 216555 & JN040500 & JN040500 \\
\hline Knufia epidermidis & CBS 120353 & NG_042475 & NR_111330 \\
\hline Knufia perforans & CBS 885.95 & JN040506 & NG_042586 \\
\hline Leptoxyphium madagascariense & CBS 124766 & GQ303308 & GQ303277 \\
\hline Metulocladosporiella musae & CBS 161.74 & DQ008161 & DQ008137 \\
\hline Metulocladosporiella musicola & CBS 113873 & DQ008135 & DQ008159 \\
\hline Minimelanolocus aquaticus & MFLUCC 15-0414 & KR215612 & NR_154181 \\
\hline Minimelanolocus submersus & KUMCC 15-0206 & KX789215 & KX789212 \\
\hline Phaeococcomyces aloes & CPC 21873 & KF777234 & NR_132069 \\
\hline Phaeococcomyces catenatus & CBS 650.76 & - & AF050277 \\
\hline Phaeosaccardinula coffeicola & COF25 & MH345729 & MH345730 \\
\hline Phaeosaccardinula dendrocalami & IFRDCC 2649 & KF667244 & NR_132894 \\
\hline Phaeosaccardinula dendrocalami & IFRDCC 2663 & KF667246 & KF667243 \\
\hline Phaeosaccardinula ficus & MFLUCC 10-0009 & HQ895837 & NR_132850 \\
\hline Phaeosaccardinula multiseptata & IFRDCC 2639 & KF667246 & KF667243 \\
\hline Strelitziana malaysiana & CPC 24874 & KR476766 & KR476731 \\
\hline Trichomerium bambusae & MFLU 16-2286 & - & KX845435 \\
\hline Trichomerium deniqulatum & MFLUCC 10-0884 & JX313660 & JX313654 \\
\hline Trichomerium chiangmaiensis & COF18 & MH345728 & MH345731 \\
\hline Trichomerium eucalypti & CBS 143443 & MG386121 & MG386068 \\
\hline Trichomerium foliicola & MFLUCC10-0078 & JX313661 & NR_144963 \\
\hline Trichomerium gleosporum & MFLUCC10-0087 & JX313662 & JX313656 \\
\hline Trichomerium siamensis & MFLUCC 12-0105 & - & KP744468 \\
\hline Vonarxia vagans & CPC 15152 & FJ839673 & FJ839637 \\
\hline Vonarxia vagans & CBS 123533 & FJ839672 & NR_132830 \\
\hline
\end{tabular}

\section{Results}

\section{Phylogenetic analyses}

New nucleotide sequences generated in this study were deposited in GenBank (Table 1). Results of the individual LSU and ITS trees (results not shown) indicated that there was no significant conflict between the topologies and respective clades in each loci. Therefore, the LSU and ITS loci were concatenated into a single dataset for analysis. After exclusion of ambiguously aligned regions, the final dataset included 48 isolates with an alignment length of 1724 characters (including gaps). With parsimony analysis, 942 characters were constant and 595 parsimonyinformative. The parsimony analysis of the data matrix resulted in 12 equally parsimonious trees and the first tree $(\mathrm{TL}=3,370$ steps, $\mathrm{CI}=0.396, \mathrm{RI}=0.609, \mathrm{HI}=0.604, \mathrm{RC}=0.241)$. A best 
scoring RAxML tree resulted with the value of Likelihood: -16510.941529 . The ML analyses showed similar tree topologies and was congruent to those obtained in MP analysis and the phylogenetic tree resulting from the analysis of two loci concatenated is rooted using Leptoxyphium madagascariense (CBS 124766) (Fig. 1). The phylogenetic tree of the partial LSU and ITS loci produced by using ML and MP analysis shows that the families of the order Chaetothyriales generally resolved into well supported clades. Trichomerium chiangmaiensis sp. nov. formed a distinct clade which is sister to species including Trichomerium foliicola, Trichomerium gleosporum and Trichomerium eucalypti. Phylogenetic analysis observation that Phaeosaccardinula coffeicola is distinct evolutionary entity and was recognized as basal lineage for all other Phaeosaccardinula isolates.

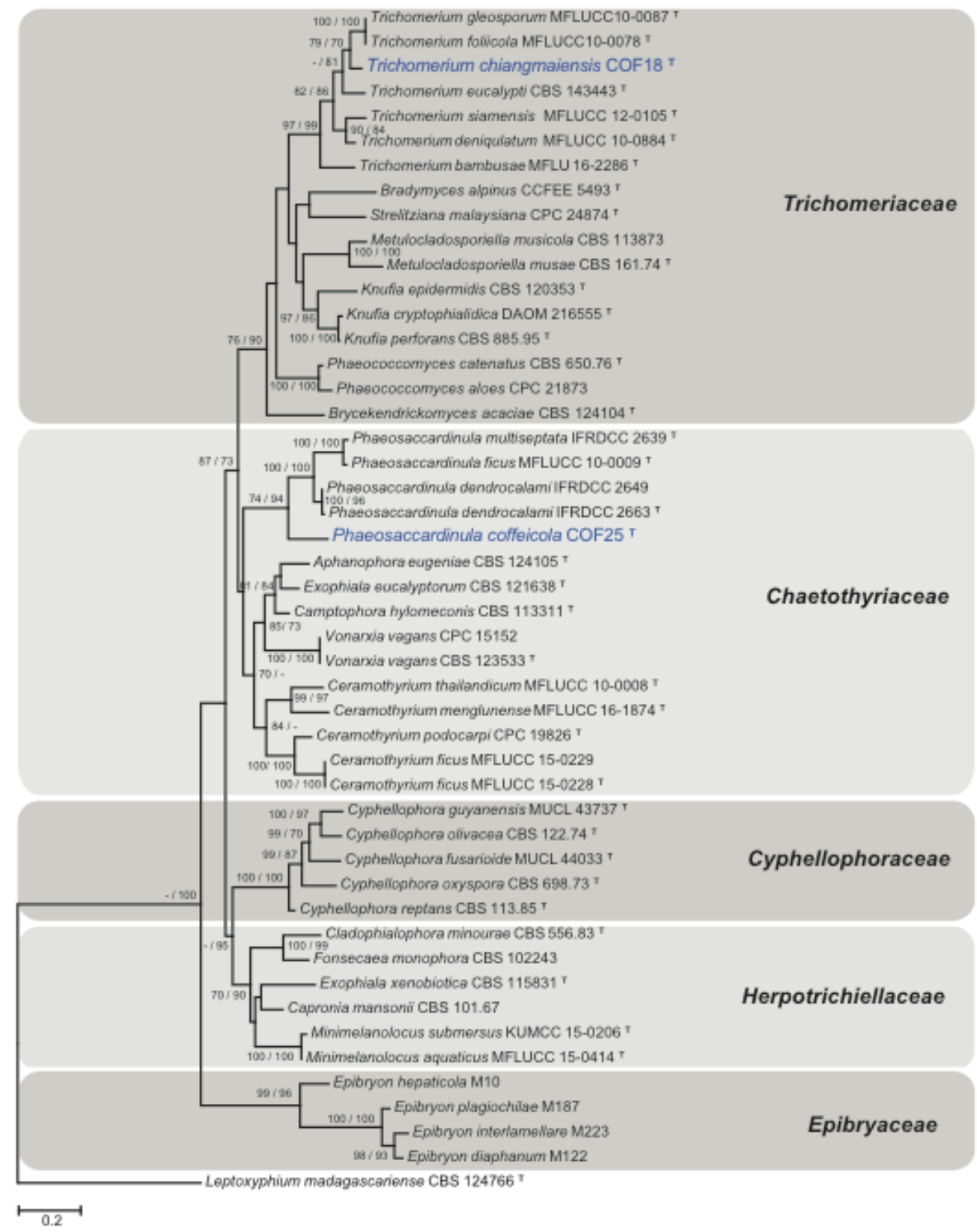

Figure 1 - Consensus tree resulting from a maximum likelihood analysis of a combined LSU and ITS sequence alignment for taxa of Chaetothyriaceae, Trichomeriaceae and other species in Chaetothyriales. Families are indicated in coloured blocks. RAxML bootstrap support values (MLB above $70 \%$ ) and maximum parsimony bootstrap support values (MPB above $70 \%$ ) are given at the nodes (MLB/MPB). The scale bar represents the expected number of changes per site. The tree is rooted to Leptoxyphium madagascariense (CBS 124766). The new sequences used in this study are in blue and type sequences are indicate by ${ }^{\mathrm{T}}$. 


\section{Taxonomy}

Phaeosaccardinula coffeicola Maharachch., Haituk \& Cheew., sp. nov.

Fig. 2

Index Fungorum number: IF554763; Facesoffungi number: FoF04392

Etymology - coffeicola referring to the host on which the taxon was found.

Foliar epiphytes growing on the upper surface of living leaves forming a soot-like coating. Sexual morph: Mycelium superficial, black, hyphae-like, dark brown to black, reticulate to branched, constricted at the septa. Ascomata 171-215 $\times 134-172 \mu \mathrm{m}(\overline{\mathrm{x}}=193 \times 153 \mu \mathrm{m}, \mathrm{n}=10)$, scattered on upper surface of living leaves of Coffea arabica, superficial, globose, dull black, lacking setae, thick-walled, inwardly of hyaline of textura prismatica, dark brown to brown towards the outside, comprised 3-4 layers of textura angularis. Asci 37-54 × 10-26 $\mu \mathrm{m}(\overline{\mathrm{x}}=46 \times 18 \mu \mathrm{m}, \mathrm{n}=10)$, 4-6spored, bitunicate, oblong-ellipsoid when young, subglobose to oval when mature, with short pedicel, ocular chamber not visible in mature asci. Ascospores $24-33 \times 8-12 \mu \mathrm{m}(\overline{\mathrm{x}}=29 \times 10 \mu \mathrm{m}$, $\mathrm{n}=10$ ) overlapping 2-4-seriate, hyaline, olivaceous green at the septa of mature ascospores, oblong-ellipsoid, muriform, with 5-7 transversal septa and 3-5 longitudinal septa, constricted at the septum, with mucilaginous sheath (absent in some mature ascospores) germ tubes developing from numerous cells. Asexual morph: Undetermined.

Culture characters - Conidia germinating on PDA at $25{ }^{\circ} \mathrm{C}$ for $24 \mathrm{~h}$, Colonies on PDA growing $2 \mathrm{~cm}$ diam after 60 days, surface brown, spreading, velvety, dense floss on the surface, pale brown and rough at the margin. No asexual state produced on PDA after 60 days.

Material examined - Thailand, Chiang Mai Province, Khun Chang Khian Highland Research Station, on living leaves of Coffea arabica L. (Rubiaceae), 21 December 2014, S.S.N Maharachchikumbura (COF25, holotype), - ex-type culture in SQUCC 12166.

Notes - Phaeosaccardinula coffeicola forms a separate cluster in the combined phylogeny, as basal sister to a group including $P$. dendrocalami, $P$. ficus and $P$. multiseptata which were isolated from on living leaf of Dendrocalamus brandisii, on living leaf of Ficus sp. and on living leaf of Dillenia pentagyna respectively (Chomnunti et al. 2012b, Yang et al. 2014). It differs from its closest phylogenetic neighbours; $P$. dendrocalami $($ asci $=57-70 \times 27-41 \mu \mathrm{m}$; ascospores $=37-49$ $\times 11-15 \mu \mathrm{m}), P$. ficus $($ asci $=120-185349-64 \mu \mathrm{m}$; ascospores $=33-56 \times 10-17 \mu \mathrm{m}$ ) and $P$. multiseptata $($ asci $=55-69 \times 30-40 \mu \mathrm{m}$; ascospores $=38-47 \times 13-16 \mu \mathrm{m})$ by its smaller asci and ascospores $($ asci $=37-54 \times 10-26 \mu \mathrm{m}$; ascospores $=24-33 \times 8-12 \mu \mathrm{m})$.

Trichomerium chiangmaiensis Maharachch., Pakdeeniti \& Cheew., sp. nov.

Fig. 3

Index Fungorum number: IF554764; Facesoffungi number: FoF04393

Etymology - named after the region where it was isolated.

Epiphytic or saprobic on the upper surface of leaves. Superficial hyphae, branched, septate, slightly constricted at the septa, pale brown to dark brown, hyphal networks cover the surface of hosts.Foliar epiphytes growing on the upper surface of living leaves forming a soot-like coating Asexual morph: Stroma none. Setae and hyphopodia absent. Conidiophore micronematous, mononematous; usually very short, pale brown, thick denticles develop from swollen hyphal cells but are not cut off by septa. Conidiogenous cells monoblastic, integrated, intercalary, determinate, cylindrical, denticulate; denticles stout, cylindrical. Conidia arms 39-58 $\times 7-9 \mu \mathrm{m}(\overline{\mathrm{x}}=50 \times 8 \mu \mathrm{m}$, $\mathrm{n}=10$ ), solitary, dry, pleurogenous, branched, with usually 4 arms, sometime up to 5 arms, 3-5-septate, pale olivaceous or brown, smooth; arms subulate, multiseptate, tapering to the apex, with rounded ends; conidia also have a fifth branch of 1-2 cells tapering to a subobtuse apex. Sexual morph: Undetermined.

Culture characters - Conidia germinating on PDA at $25{ }^{\circ} \mathrm{C}$ for 18 hours, germ tubes appearing from each branch of conidia, hyaline to bluish, but becoming dark brown to black. Colonies reaching $1 \mathrm{~cm}$ diameter after 7 days on PDA at $25{ }^{\circ} \mathrm{C}$, colonies, velvety surface, dark 
brown pale brown at the margin, dark brown sparse aerial hyphae outer region. Conidia produced in PDA after 15 days incubation.
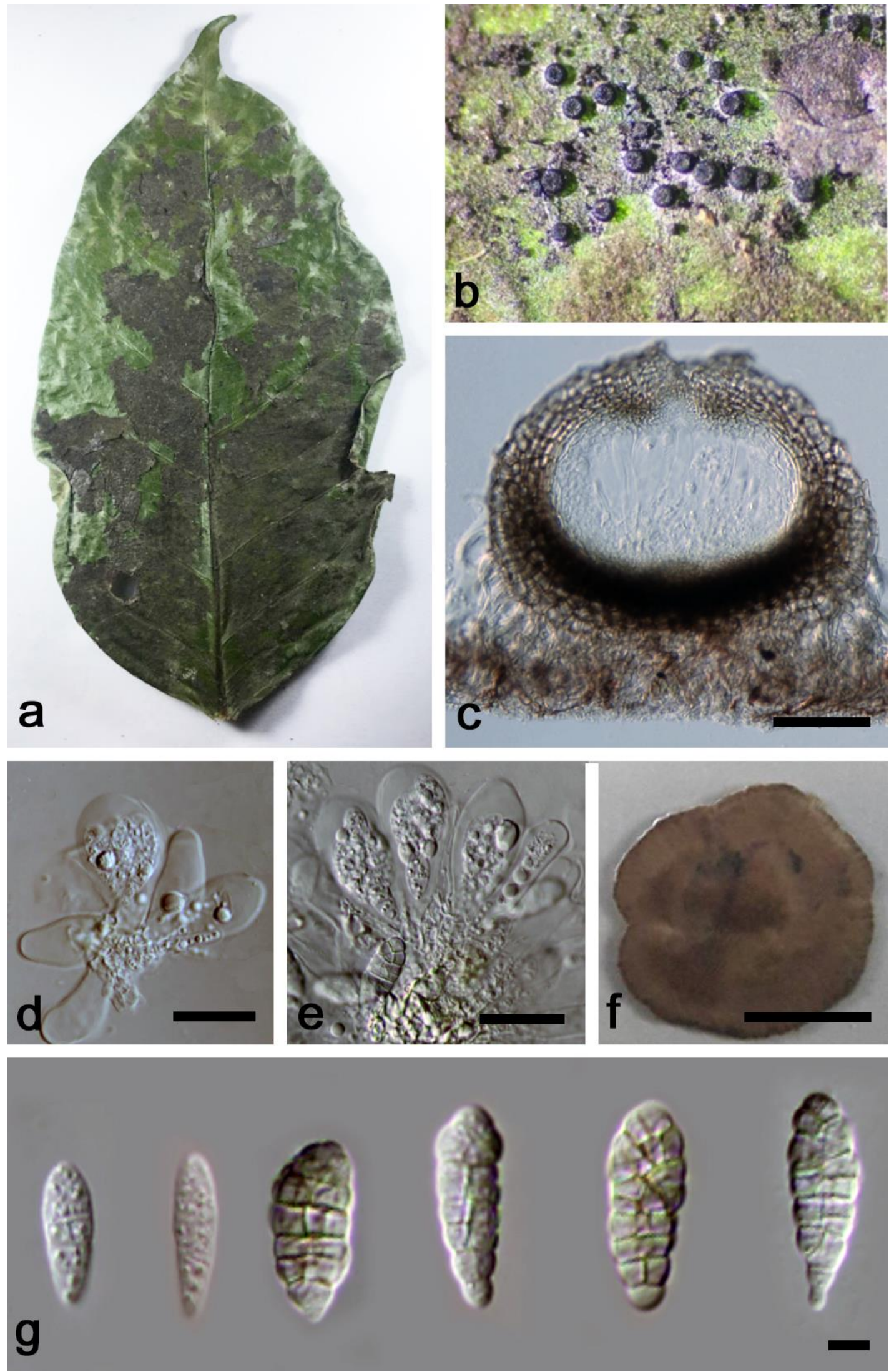

Figure 2 - Phaeosaccardinula coffeicola (COF25, holotype). a-b Sooty molds on leaf surface. c Vertical sections of ascoma. d-e Asci. f Colonies on media. g Ascospores. Scale bars: c-e, $=30$ $\mu \mathrm{m}, \mathrm{g}=5 \mu \mathrm{m}$. 
Material examined - Thailand, Chiang Mai Province, Mae Rim, Nong Hoi Royal Project, on living leaves of Coffea arabica L. (Rubiaceae), 15 December 2014, S.S.N Maharachchikumbura (COF18, holotype) - ex-type culture in SQUCC 12167.

Notes - Trichomerium chiangmaiensis is introduced as a new species based on its asexual morphs isolated from the living leaves of Coffea arabica. Trichomerium chiangmaiensis phylogenetically closely related to $T$. eucalypti, T. foliicola and T. gleosporum. The genus Trichomerium has Tripospermum asexual morphs (Crous et al. 2014) and the asexual morph of $T$. chiangmaiensis is comparable with T. eucalypti and T. gloeosporum. Trichomerium chiangmaiensis can be distinguished from $T$. eucalypti (conidial arms size $=30-80 \times 8-10 \mu \mathrm{m}$ ) by its smaller conidial arms (size $=39-58 \times 7-9 \mu \mathrm{m}$ ). Furthermore, the microconidia present on the T. eucalypti (Crous et al. 2017) were not observed on the T. chiangmaiensis. Trichomerium gloeosporum is distinct from $T$. chiangmaiensis by its smaller conidial arms (size $=29-35 \times 5-7 \mu \mathrm{m}$ ), longer basal, and apical appendages.

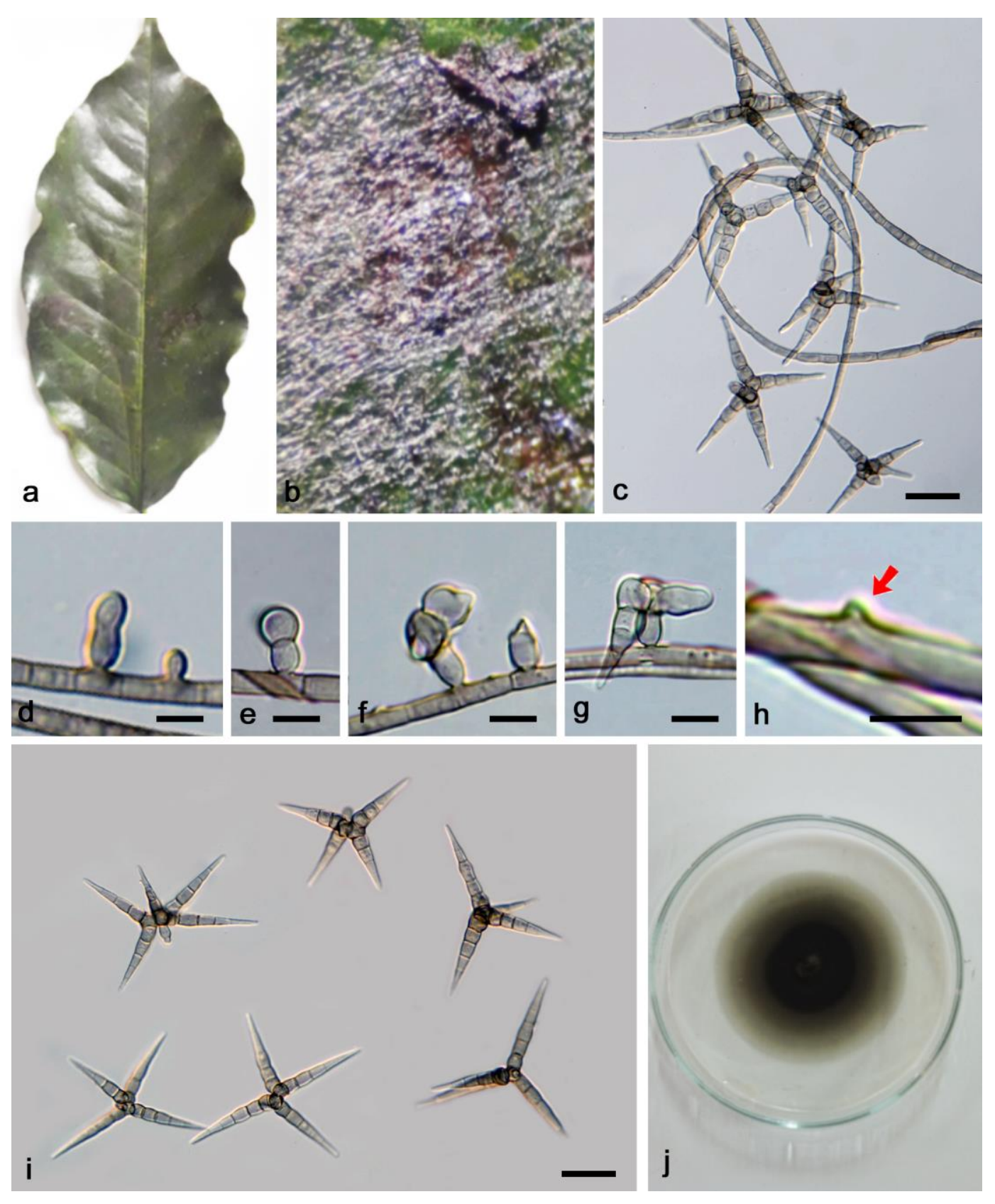

Figure 3 - Trichomerium chiangmaiensis. a-b Sooty molds on host. c Conidia and conidiophore. $\mathrm{d}-\mathrm{g}$ Immature conidia at various stages of development attached to the prostrate mycelium. h Denticulate. i-f Conidia. j Colonies on media. Scale bars: c, $\mathrm{i}-\mathrm{k}=30 \mu \mathrm{m}, \mathrm{d}-\mathrm{h}=10 \mu \mathrm{m}$. 


\section{Acknowledgements}

We would like to acknowledge financial support from Sultan Qaboos University and Oman Animal and Plant Genetic Resources Center through the project EG/AGR/CROP/16/01. We also received support from the Chiang Mai University Postdoctoral Fellowship (2017).

\section{References}

Barr ME. 1976 - Perspectives in the Ascomycotina. Memoirs of the New York Botanical Garden 28, 1-8.

Barr ME. 1987 - Prodromus to class Loculoascomycetes. Publ. by the author. Amherst, Massachusett.

Batista AC, Ciferri R. 1962 - The Chaetothyriales. Sydowia 3, 1-129.

Chomnunti P, Bhat DJ, Jones EGB, Chukeatirote E et al. 2012a - Trichomeriaceae, a new sooty mould family of Chaetothyriales. Fungal Diversity 56(1), 63-76.

Chomnunti P, Ko TWK, Chukeatirote E, Hyde KD et al. 2012b - Phylogeny of Chaetothyriaceae in northern Thailand including three new species. Mycologia 104(2), 382-395.

Chomnunti P, Hongsanan S, Aguirre-Hudson B, Tian Q et al. 2014 - The sooty moulds. Fungal Diversity $66,1-36$.

Crous PW, Wingfield MJ, Schumacher RK, Summerell BA et al. 2014 - Fungal Planet description sheets: 281-319. Persoonia: Molecular Phylogeny and Evolution of Fungi 33, 212-289.

Crous PW, Wingfield MJ, Burgess TI et al. 2017 - Fungal Planet description sheets: 625-715. Persoonia: Molecular Phylogeny and Evolution of Fungi 39, 270-467.

Dong W, Hyde KD, Bhat DJ, Zhang H. 2018 - Introducing Aculeata aquatica gen. et sp. nov., Minimelanolocus thailandensis sp. nov. and Thysanorea aquatica sp. nov. (Herpotrichiellaceae, Chaetothyriales) from freshwater in northern Thailand. Mycological Progress 17, 617-629.

Felsenstein J. 1985 - Confidence limits on phylogenies: an approach using the bootstrap. Evolution 39(4), 783-791.

Gueidan C, Aptroot A, da Silva Cáceres ME, Badali H, Stenroos S. 2014 - A reappraisal of orders and families within the subclass Chaetothyriomycetidae (Eurotiomycetes, Ascomycota). Mycological progress 13,1027-1039

Gueidan C, Villaseñor CR, De Hoog GS, Gorbushina AA et al. 2008 - A rock-inhabiting ancestor for mutualistic and pathogen-rich fungal lineages. Studies in Mycology 61, 111-119.

Hansford CG. 1946 - The foliicolous ascomycetes, their parasites and associated fungi, Mycological Papers 15, 1-240.

Hennings PC. 1905 - Fungi amazonici IV. a cl. Ernesto Ule collecti. Hedwigia 44, 57-71.

Hongsanan S, Tian Q, Hyde KD, Hu DM. 2016 - The asexual morph of Trichomerium gloeosporum. Mycosphere 7(9), 1473-1479.

Hughes SJ. 1976 - Sooty moulds. Mycologia 68, 693-820.

Hyde KD, Hongsanan S, Jeewon R, Bhat DJ et al. 2016 - Fungal diversity notes 367-490: taxonomic and phylogenetic contributions to fungal taxa. Fungal Diversity 80, 1-270.

Index Fungorum 2018 - Available from: http://www.indexfungorum.org/Names/Names.asp. Accessed: March 2018.

Jayasiri SC, Hyde KD, Ariyawansa HA, Bhat DJ et al. 2015 - The Faces of Fungi database: fungal names linked with morphology, phylogeny and human impacts. Fungal Diversity 74, 3-18.

Kirk PM, Cannon PF, Minter DW, Stalpers JA. 2008 - Dictionary of the Fungi 10th edn, CABI Bioscience, UK.

Kumar S, Stecher G, Tamura K. 2016 - MEGA7: molecular evolutionary genetics analysis version 7.0 for bigger datasets. Molecular Biology and Evolution 33, 1870-1874.

Liu XY, Udayanga D, Luo ZL, Chen LJ et al. 2015 - Backbone tree for Chaetothyriales with four new species of Minimelanolocus from aquatic habitats. Fungal Biology 119(11), 1046-1062. 
Maharachchikumbura SSN, Hyde KD, Groenewald JZ, Xu J, Crous PW. 2014 - Pestalotiopsis revisited. Studies in Mycology 79, 121-186.

Nylander JA. 2004 - MrModeltest v2. Program distributed by the author. Evolutionary Biology Centre, Uppsala University, Uppsala, Sweden

Réblová M, Untereiner WA, Réblová K. 2013 - Novel evolutionary lineages revealed in the Chaetothyriales (Fungi) based on multigene phylogenetic analyses and comparison of ITS secondary structure. PLoS One 8(5), e63547.

Reynolds DR. 1971 - The sooty mould ascomycete genus Limacinula. Mycologia 63, 1173-1209.

Reynolds DR. 1983 - Foliicolous ascomycetes. 5. The capnodiaceous clypeate genus Treubiomyces. Mycotaxon 17, 349-360.

Silvestro D, Michalak I. 2012 - raxmlGUI: a graphical front-end for RAxML. Organisms Diversity \& Evolution 12 (4), 335-337.

Swofford DL. 2003 - PAUP*: phylogenetic analysis using parsimony, version 4.0 b10.

Teixeira MDM, Moreno LF, Stielow BJ, Muszewska A et al. 2017 - Exploring the genomic diversity of black yeasts and relatives (Chaetothyriales, Ascomycota). Studies in Mycology $86,1-28$.

Vilgalys R, Hester M. 1990 - Rapid genetic identification and mapping of enzymatically amplified ribosomal DNA from several Cryptococcus species. Journal of Bacteriology 172(8), 42384246.

White TJ, Bruns T, Lee S, Taylor J. 1990 - Amplification and direct sequencing of fungal ribosomal RNA genes for phylogenetics. In: Innis, M.A., Gelfand, D.H., Sninsky, J.J. \& White, T.J. (Eds.) PCR protocols: A Guide to Methods and Applications. Academic Press, New York, USA, pp. 315-322.

Wijayawardene NN, Hyde KD, Rajeshkumar KC, Hawksworth DL et al. 2017 - Notes for genera: Ascomycota. Fungal Diversity 86, 1-594.

Wijayawardene NN, Hyde KD, Lumbsch HT, Liu JK et al. 2018 - Outline of Ascomycota: 2017. Fungal Diversity 88, 167-263.

Winka K, Eriksson OE, Bång A. 1998 - Molecular evidence for recognizing the Chaetothyriales. Mycologia 90(5), 822-830.

Yang H, Chomnunti P, Ariyawansa HA, Wu HX, Hyde KD. 2014 - The genus Phaeosaccardinula (Chaetothyriales) from Yunnan, China, introducing two new species. Chaing Mai Journal of Science 41, 873-884. 